\title{
Detección de patógenos asociados a la enfermedad punta morada en los cultivos de papa y tomate en Guatemala
}

\author{
Detection of pathogens associated to potato purple top disease in potato \\ and tomato crops in Guatemala \\ Julio E. Berdúo-Sandoval ${ }^{1}$, José A. Ruiz-Chután ${ }^{1,2}$, Luis Méndez ${ }^{1}$, Luis Mejía ${ }^{3}$, \\ Douglas Maxwel1 ${ }^{4}$, Amílcar Sánchez-Pérez ${ }^{1 *}$ \\ ${ }^{1}$ Facultad de Agronomía, Universidad de San Carlos de Guatemala, Guatemala \\ ${ }^{2}$ Department of Crop Sciences and Agroforestry, Czech University of Life Sciences Prague, Czech Republic \\ ${ }^{3}$ Universidad de Manizales, Colombia, ${ }^{4}$ Department of Plant Pathology, University of Wisconsin
}

*Autor al que se dirige la correspondencia: gramisp@hotmail.com

Recibido: 01 de julio 2019 / Revisión: 13 de julio 2020 / Aceptado: 05 de agosto 2020

Resumen

T a punta morada es una enfermedad que afecta la producción de algunas especies de solanáceas como la papa y Lel tomate, causando enrollamiento en las puntas de las hojas con una marcada coloración morada, decaimiento temprano de la planta y en la papa se observa tuberización aérea. Como patógenos asociados a la enfermedad se consideran al fitoplasma BLTVA y la bacteria Candidatus Liberibacter solanacearum. Dada la similitud en la sintomatología foliar que generan ambos patógenos, es difícil precisar cuál de ellos está implicado en la enfermedad. En Guatemala, existen reportes de la sintomatología típica de punta morada en las principales zonas productoras de papa y tomate, desconociéndose el agente asociado. La investigación determinó cuál de los dos patógenos reportados está asociados a la enfermedad en 12 municipios productores de papa y/o tomate en el país. Se realizaron amplificaciones de ADN con cebadores específicos para cada patógeno asociado a la enfermedad. Por la alta incidencia del fitoplasma BLTVA en las muestras de papa (73.9\%), en comparación a $C$. Liberibacter solanacearum (26\%), este es considerado como el patógeno asociado más importante en papa. En las muestras de tomate, la incidencia del fitoplasma BLTVA (29.8\%) y C. Liberibacter solanacearum del (27.6\%) fue similar. Además, sobresale el primer reporte de la detección del fitoplasma BLTVA afectando el cultivo de tomate en Guatemala. Se sugiere un monitoreo constante, mediante métodos moleculares, para un diagnóstico certero y establecer medidas de manejo de la enfermedad para evitar su diseminación hacia zonas aún no afectadas.

Palabras claves: Punta morada, papa rayada, fitoplasma BLTVA, Candidatus Liberibacter solanacearum

Abstract

$\mathrm{T}$ The potato purple top is a disease that affects the production of some solanaceous species such as potatoes and tomatoes, causing curl at the tips of the leaves with a marked purple coloration, early decay of the plant, and aerial tuberization is observed in the potato. BLTVA phytoplasma and Candidatus Liberibacter solanacearum are considered as pathogens associated with the disease. Given the similarity in foliar symptoms generated by both pathogens, it is difficult to determine which one is involved in the disease. There are reports of the typical potato purple top symptoms in the main potato and tomato producing areas in Guatemala, being unknown the associated agent. The research determined which of the two reported pathogens is associated with the disease in 12 potatoes and/or tomato producing areas in the country. We performed DNA amplification with specific primers for each disease-associated pathogen. Due to the high incidence of BLTVA phytoplasma in potato samples (73.9\%), compared to $C$. liberibacter solanacearum $(26 \%)$, this is considered the most important associated pathogen in potatoes. In tomato samples, the incidence of BLTVA phytoplasma (29.8\%) and $C$. liberibacter solanacearum (27.6\%) was similar. Besides, the first report of the detection of the BLTVA phytoplasma affecting tomato cultivation in Guatemala stands out. Using molecular methods, constant monitoring is suggested for an accurate diagnosis and to establish management measures for the disease to prevent its spread to areas not yet affected.

Keywords: Potato purple top, zebra chip, BLTVA phytoplasm, Candidatus Liberibacter solanacearum 


\section{Introducción}

En Guatemala, la papa (Solanum tubersosum L.) y el tomate (Solanum lycopersicum L.) son dos de los cultivos de mayor importancia para el país y ambos son afectados por la enfermedad denominada como punta morada (Munyaneza et al., 2007). Para la población agrícola de la región occidental de Guatemala, la papa forma parte imporante de su dieta básica y según los últimos datos reportados (Ministerio de Agricultura Ganadería y Alimentación [Maga], 2016), se obtuvo una cosecha de 1,187,260 Tm generando 12,793 empleos permanentes. En cuanto al tomate, se considera como uno de los cultivos hortícolas de mayor importancia económica para el país, con una última cosecha reportada de 318,181.8 Tm (Maga, 2016).

Estos dos cultivos se han visto afectados por la enfermedad conocida como punta morada, la cual se caracteriza por causar enrollamiento de las puntas y los bordes de las hojas hacia el haz con una marcada coloración morada, una moderada proliferación de los brotes, entrenudos cortos, hinchamiento de los nudos, tuberización aérea en el caso de la papa y un decaimiento temprano de la planta (Longoria-Espinoza et al., 2013; Munyaneza et al., 2007; Santos-Cervantes et al., 2010). Esta enfermedad ha sido asociada con la presencia de al menos ocho diferentes cepas de fitoplasmas alrededor del mundo, siendo los grupos de fitoplasmas comunmente mencionados, como causantes de la enfermedad, el amarrillamiento del áster (16Srl-A y 16Srl-B), la escoba de bruja del maní (16Srll), proliferación del trébol (16SrVl-A) y stolbur (16SrX11) (Santos-Cervantes et al., 2010).

Los métodos desarrollados para la detección del fitoplasma Beet leafhopper transmitted virescence agent (BLTVA), asociado a la enfermedad de la punta morada, están basados en la técnica de PCR y han sido desarrollados por varios autores (Crosslin et al., 2006; El-banna et al., 2007; Munyaneza et al., 2007) con algunas variantes entre ellos, como las concentraciones de algunos reactivos y las condiciones del PCR. En un primer ciclo de reacciones, se utilizan los cebadores universales $\mathrm{P} 1 / \mathrm{P} 7$, los cuales generan un amplicón de 1.8 $\mathrm{Kb}$ correspondiente a un segmento del ribosoma $16 \mathrm{~S}$, la región espaciadora entre el ribosoma $16 \mathrm{~S}$ y el $23 \mathrm{~S}$ y una pequeña parte del ribosoma 23S. Posteriormente, mediante un segundo ciclo de reacciones (PCR anidada), se emplean los cebadores fU5/BLTVAint (Crosslin et al., 2006) o los cebadores R16F2n/R16R2 (Lee et al., 2004), los cuales son específicos para la detección de fitoplasmas del grupo 16SrVI.
La enfermedad de la punta morada ha sido reportada en varios países. Por ejemplo, durante la epidemia de punta morada, ocurrida en 2002 en la región de Columbia Basin en Washington y Oregon, la enfermedad fue asociada al fitoplasma denominado como BLTVA (Lee et al., 2004). En el estado de México se determinó que dicha enfermedad era causada por "Candidatus Phytoplasma asteris" (Gutiérrez-Ibáñez et al., 2012). La misma enfermedad también fue reportada y asociada a la presencia de fitoplasmas en el Valle de Toluca, México (Gutiérrez-Ibáñez et al., 2013). En Ecuador se reportó por primera vez la presencia de Candidatus Phytoplasma aurantifolia (16Srll) asociado a la punta morada (Caicedo et al., 2015). La presencia del fitoplasma BLTVA, miembro del grupo 16SrVI, también fue señalada en el estudio de Crosslin y colaboradores (2011).

En cuanto a los vectores de fitoplasmas asociados a la enfermedad de punta morada, se mencionan varias especies de chicharritas (Homoptera: Cicaelidae) como Macrosteles orientalis, M. fascifrons, $M$. striiforns, Scleroracus avopictus, Orosius albicinctus, Alebroides dravidamus (Maramorosch, 1998). También se reportan a las especies Circulifer tenellus y Ceratagallia spp. (Munyaneza, 2005; Munyaneza et al., 2006, 2007) y los géneros Empoasca y Aceratagallia en México (Almeyda et al., 2004). En el estudio realizado en México, Garzón y colaboradores (2004) reportan al psílido Bactericera cockerelli como vector de fitoplasmas asociados a punta morada en papa. Por su parte, Almeyda y colaboradores (2002) indican que $B$. cockerelli colectado en plantaciones de tomate con síntomatología típica de punta morada, fue positivo para fitoplasma. De esta forma se demuestra que esta especie de psílido también es un potencial vector de fitoplasmas asociados a la enfermedad de punta morada en tomate.

Otra enfermedad importante que ha sido documentada por ocurrir en plantaciones de producción comercial de papa en el suroeste de los Estados Unidos, México y Guatemala, ha sido denominada como Zebra Chip o papa rayada. Dicha enfermedad fue observada por primera vez en México en 1994 y posteriormente en los Estados Unidos en Texas (Secor \& Rivera-Varas, 2004). El impacto negativo de la enfermedad se evidenció durante los brotes ocurridos en México y los Estados Unidos del 2004 al 2006, en donde se generaron pérdidas millonarias para cultivadores y procesadores de la papa. Las pérdidas son debido a la coloración café que resulta luego del proceso de fritura del tubérculo, haciendo el producto final, las papalinas o chips, comercialmente inaceptables (Lin et al., 2009; Munyaneza, et 
al., 2007) llevando incluso al abandono de los campos de cultivo (Goolsby et al., 2007). Los costos incurridos para el manejo de la enfermedad y su vector alcanzan cifras millonarias en compras de ingredientes activos y aplicaciones (Greenway \& Rondon, 2018).

La sintomatología foliar en papa y tomate es similiar a la que se presenta con la enfermedad de la punta morada causada por fitoplasmas (Gutiérrez-Ibáñez et al., 2013). Los síntomas van desde una clorosis, tallos torcidos con apariencia en zigzag y nódulos agrandados, hasta tubérculos aéreos, descoloramiento vascular y hojas calcinadas y marchitas que llegan prematuramente a la senescencia (Crosslin \& Munyaneza, 2009; Secor et al., 2009). Los tubérculos presentan una coloración café en el aro vascular y rayos medulares que se extienden de forma longitudinal sobre todo el tubérculo, mostrando una pobre o nula germinación de las lenticelas (Lin et al., 2009). La enfermedad también induce la necrosis del tubérculo (Secor et al., 2009).

En cuanto al agente causal de la enfermedad Zebra Chip; Liefting y colaboradores (2008) lograron asociar la enfermedad con lo que para entonces constituía una nueva bacteria, la cual se denominó inicialmente como Candidatus Liberibacter psyllaurous (Hansen et al., 2008) y posteriormente Candidatus Liberibacter solanacearum. Esta misma bacteria fue reportada por Abad y colaboradores (2009), quienes después de una amplificación específica con los cebadores OA2/ OI2c (Liefting et al., 2008, 2009), a partir de plantas con la sintomatología típica de la enfermedad, realizaron la comparación de las secuencias obtenidas con las reportadas en Nueva Zelanda, constituyendo así el primer reporte de $C$. Liberibacter solanacearum asociada a papa, en los Estados Unidos. Posteriormente, a través de las muestras obtenidas de campos de cultivo de papa en los Estados Unidos, México y Guatemala, Secor y colaboradores (2009) también reportaron que dicha enfermedad se encontraba asociada a la presencia de la bacteria Candidatus Liberibacter solanacearum. Además, los autores añaden que las secuencias de la región $16 \mathrm{~S}$ de las tres regiones geográficas representadas, son casi idénticas a las secuencias de la región $16 \mathrm{~S}$ reportadas en Nueva Zelanda.

La transmisión de esta bacteria puede ser por medio de injerto, semilla no botánica en el caso de papa (tubérculo), semilla botánica en el caso de zanahoria e insectos vectores como el psílido $B$. cockerelli en especies de la familia Solanaceae (Bertolini et al., 2015; Delgado-Ortíz et al., 2019; Liefting et al., 2009; Secor et al., 2009). La bacteria también ha sido reportada como patógeno en algunas especies de la fa- milia Apiaceae como la zanahoria (Daucus carota L.) (Ben-Othmen et al., 2018) y apio (Apium graveolens L.) (Teresani et al., 2014) siendo los vectores las especies B. trigonica (Alfaro-Fernández et al., 2012) y Trioza apicalis (Munyaneza et al., 2010).

En Guatemala ha sido reportada la presencia de $C$. Liberibacter solanacerum en papa (Palmieri et al., 2012; Secor et al., 2009) y en tomate (Mejía et al., 2010). Sin embargo, existen pocos registros sobre la detección del fitoplasma BLTVA en el cultivo de papa, y más escasos aún, en el cultivo de tomate. Debido a la similitud en la sintomatología foliar de las enfermedades Zebra Chip y punta morada, en los cultivos de papa y tomate, existe una total incertidumbre sobre el patógeno asociado a la enfermedad denominada como punta morada por los agricultores guatemaltecos. Se desconoce si dicha enfermedad es causada en el país, únicamente por la bacteria ya reportada, o también se debe a la presencia del fitoplasma. Por esta razón, se realizaron muestreos de plantas de papa y tomate con los síntomas característicos de la enfermedad, en las principales zonas de producción de los cultivos de tomate y papa del país, con el objetivo de detectar, a través de técnicas moleculares, la presencia de uno o ambos patógenos.

\section{Materiales y métodos}

\section{Obtención del material vegetal}

Durante el período de abril a agosto del 2018, se colectaron 47 muestras de tomate y 23 de papa en algunas de las principales zonas productoras localizadas en los municipios de Antigua Guatemala, Salamá, San Jerónimo, Purulhá, San Juan Chamelco, Zunil, Amatitlán, Villa Nueva, Sanarate, Patzicía, Santa Cruz Balanyá y Jalapa. Se escogieron plantas de tomate y papa con los síntomas aéreos característicos de infección por punta morada, tomando cinco foliolos sintomáticos por cada planta. Las muestras de material vegetal fueron almacenadas en condiciones de frío y se trasladaron al Laboratorio de Biotecnología de la Facultad de Agronomía de la Universidad de San Carlos de Guatemala para realizar la extracción del ADN.

\section{Extracción del ADN}

Para la extracción del ADN se empleó el kit comercial Gentra ${ }^{\circledR}$ siguiendo la metodología propuesta por el fabricante con algunas modificaciones que se describen a continuación. Se tomó una sección de cada 
hoja de aproximadamente $4 \times 4 \mathrm{~mm}$ dentro de un tubo de $1.5 \mathrm{~mL}$ al cual se le agregaron $450 \mu \mathrm{L}$ de Cell Lysis Solution y se procedió a macerar. Seguido se agregaron $2.25 \mu \mathrm{L}$ de proteinasa $\mathrm{K}(100 \mu \mathrm{g} / \mathrm{mL})$ y se dejó incubar por $3 \mathrm{~h}$ realizando mezclas por inversión cada $30 \mathrm{~min}$. Posterior se agregaron $2.5 \mu \mathrm{L}$ de solución RNasa A (4 $\mathrm{mg} / \mathrm{mL}$ ) y se mezcló por inversión 25 veces, dejando incubar nuevamente por 45 min a $37^{\circ} \mathrm{C}$. Se dejó enfriar a temperatura ambiente y se agregaron $150 \mu \mathrm{L}$ de Protein Precipitation Solution mezclándose por inversión (aproximadamente $2 \mathrm{~min}$ ) y se incubó por $20 \mathrm{~min}$ a -20 ${ }^{\circ} \mathrm{C}$, luego fue centrifugado a $14,000 \mathrm{rpm}$ durante $4 \mathrm{~min}$ y el sobrenadamente fue transferido a un nuevo tubo.

Se agregaron $600 \mu \mathrm{L}$ de una solución fenol-cloroformo-alcohol isoamílico en una relación 25:24:1 y se mezcló por inversión, se centrífugó nuevamente a $14,000 \mathrm{rpm}$ por $10 \mathrm{~min}$ y el sobrenadante se transfirió a un nuevo tubo. Se agregaron $600 \mu \mathrm{L}$ de cloroformo-alcohol isoamílico en una relación 24:1 y se mezcló por inversión, se centrifugó por $10 \mathrm{~min}$ a 14,000 rpm y el sobrenadante se transfirió a un nuevo tubo. Se agregaron $600 \mathrm{uL}$ de isopropanol, se mezcló por inversión y después se centrifugó por 3 min a 14,000 rpm y descartando la fase líquida. Luego se agregaron $500 \mu \mathrm{L}$ de etanol al 70\% mezclando por inversión para lavar la pastilla de ADN y se centrifugó por 3 min a 14,000 rpm invirtiendo el tubo para descartar el etanol. Los tubos, con la pastilla de ADN, se dejaron secar por 10 a 15 min sobre papel absorbente. Para la hidratación del ADN se agregaron $50 \mu \mathrm{L}$ de DNA Hidratation Solution, se incubó a $65^{\circ} \mathrm{C}$ por 1 hora y finalmente se almacenó a $-20{ }^{\circ} \mathrm{C}$.

\section{Detección del fitoplasma BLTVA y la bacteria $C$. Liberibacter solanacearum}

Para la detección del fitoplasma BLTVA, se llevó a cabo un primer PCR con los cebadores universales P1/P7 y P1/Tint (Smart et al., 1996). La reacción fue preparada para un volumen total de $25 \mu \mathrm{L}$ conteniendo solución de amortiguación para PCR (1X), $\mathrm{MgCl}_{2}$ ( $2 \mathrm{mM})$, dNTP's (200 $\mu \mathrm{M}$ de cada uno), cebador ( 0.6 $\mu \mathrm{M}$ de cada uno,) TaqDNA polimerasa (2 unidades) y ADN (40 ng). Las condiciones para la PCR fueron las siguientes: Un ciclo a $94^{\circ} \mathrm{C}$ por $3 \mathrm{~min}$, seguido de 35 ciclos a $94{ }^{\circ} \mathrm{C}$ por $30 \mathrm{~s}, 55^{\circ} \mathrm{C}$ por $1 \mathrm{~min}, 72{ }^{\circ} \mathrm{C}$ por 2 min y una extensión final de $72^{\circ} \mathrm{C}$ por $10 \mathrm{~min}$. Las reacciones que generaron un fragmento de $1.8 \mathrm{~kb}$ con el par de cebadores P1/P7 o un fragmento de $1.6 \mathrm{~kb}$ con el par de cebadores P1/Tint, fueron clasificadas como positivas.
Posteriormente, se llevó a cabo una PCR anidada con los cebadores específicos fU5/BLTVAint (Lorenz et al., 1995; Smart et al., 1996) tomando como ADN molde $1 \mu \mathrm{L}$ del producto del primer PCR con los cebadores P1/P7. Las concentraciones de los reactivos y las condiciones para la PCR anidada fueron las mismas que se utilizaron en el primer ciclo de amplificaciones, cambiando únicamente el tiempo de extensión de 2 a $1 \mathrm{~min}$. Las reacciones que generaron un fragmento de aproximadamente $1.2 \mathrm{~kb}$ fueron clasificadas como positivas.

Para la detección de $C$. Liberibacter solanacearum se emplearon los cebadores específicos ClipoF/ O12c (Secor et al., 2009). La reacción fue preparada para un volumen total de $25 \mu \mathrm{L}$ utilizando los mismos reactivos y concentraciones anteriormente descritas. Las condiciones para la PCR fueron las mismas que se utilizaron para la amplificación de los fitoplasmas. Las reacciones que generaron un fragmento de 1,070 $\mathrm{pb}$ fueron clasificadas como positivas.

Las muestras se amplificaron en un termociclador Bio Rad PTC-200. Todos los productos de PCR generados fueron visualizados por electroforesis en gel de agarosa al $1.5 \%$ teñidos con bromuro de etidio ( 0.1 $\mu \mathrm{g} / \mathrm{mL}$ ) en amortiguador TAE $1 \mathrm{X}$, empleando un transiluminador de luz UV. Para la comparación del peso molecular de los fragmentos obtenidos se utilizaron los marcadores de peso molecular $3 \mathrm{~kb}$ SibEnzyme Ltd. ${ }^{\circledR}$

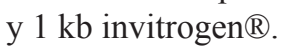

\section{Resultados}

De las 23 muestras de papa analizadas para fitoplasmas con los cebadores universales, ocho resultaron positivas, lo que representa un $34.7 \%$ de incidencia de este patógeno. En tomate, de las 47 muestras analizadas para fitoplasmas 12 resultaron positivas con los cebadores universales, representando un $25.5 \%$ de incidencia de este patógeno. Las muestras positivas generaron un fragmento de $1.8 \mathrm{~kb}$ con el uso de los cebadores $\mathrm{P} 1 / \mathrm{P} 7 \mathrm{y}$ un fragmento de $1.6 \mathrm{~kb}$ con el uso de los cebadores P1/ Tint (Figuras 1 y 2). Los resultados obtenidos fueron los mismos para ambos cebadores, ya que se amplificaron el mismo número de muestras con cada par de cebadores universales. Cuando se emplearon los cebadores específicos fU5/BLTVA, diecisiete muestras de papa amplificaron un fragmento de aproximadamente $1.2 \mathrm{~kb}$ y se consideraron positivas para el fitoplasma BLTVA, representando una incidencia del $73.9 \%$ de este patógeno en el total de muestras analizadas. En tomate, catorce muestras resultaron positivas representando un $29.8 \%$ 


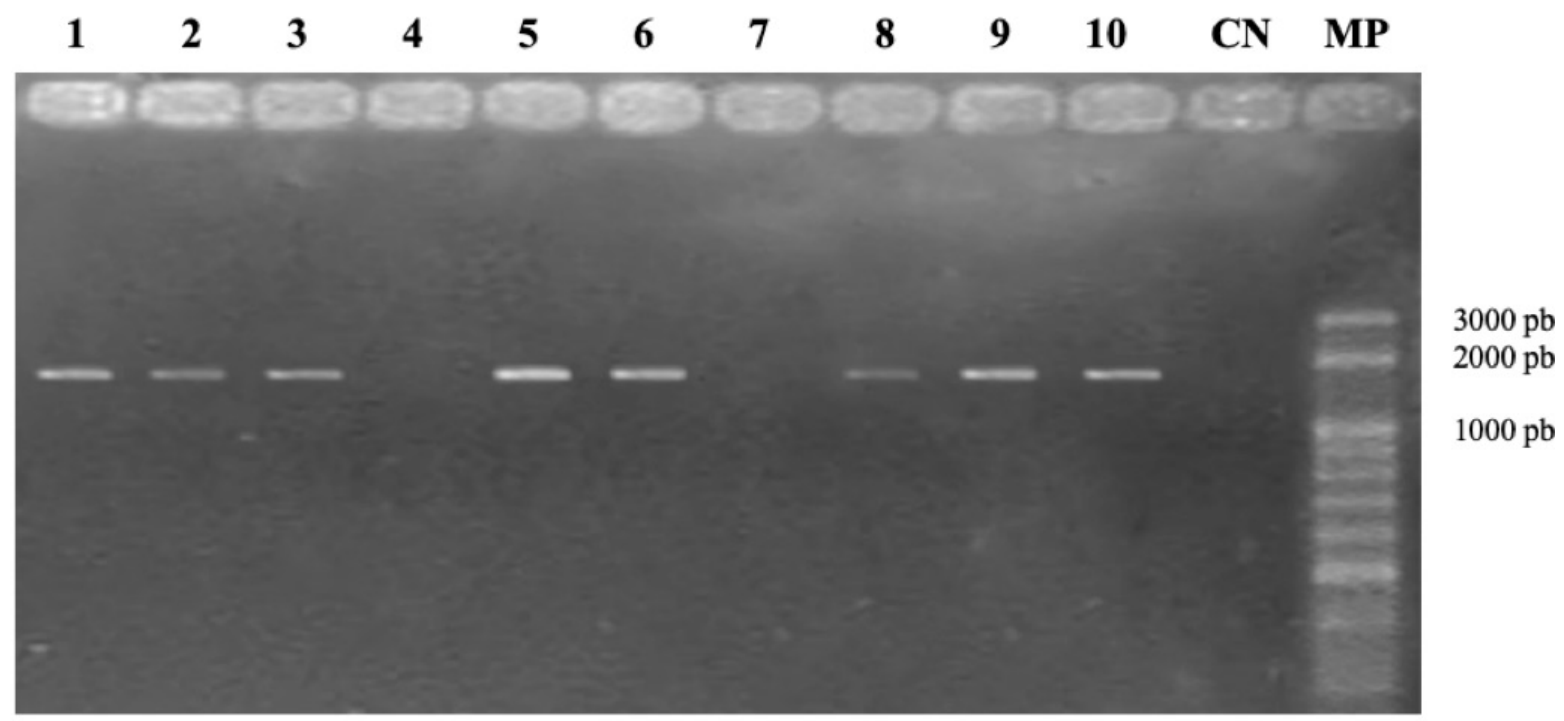

Figura 1. Productos amplificados por PCR con los cebadores P1/P7 a partir del ADN extraído de plantas de tomate y papa con síntomas de punta morada. Carrilles 1 - 4: Plantas de tomate colectadas en Antigua Guatemala (T9), Salamá (T21), San Jerónimo (T34) y Purulhá (T42). Carriles 5 - 10: Plantas de papa colectadas en Santa Cruz Balanyá (P48), Purulhá (P52), Zunil (P57) y Jalapa (P64, P67 y P68). CN: Control negativo (agua estéril). MP: Marcador de peso molecular DNA Ladder $3 \mathrm{~Kb}$ (SibEnzyme Ltd.®).

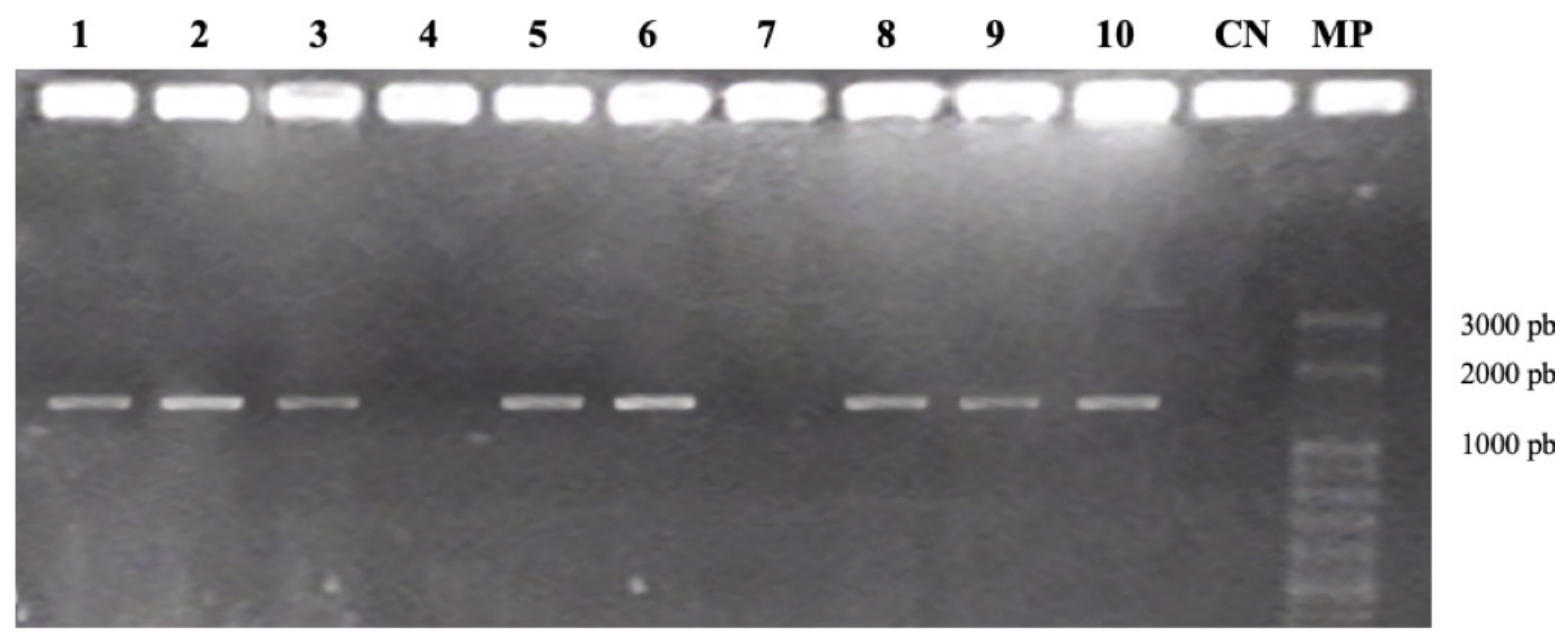

Figura 2. Productos amplificados por PCR con los cebadores P1/Tint a partir del ADN extraído de plantas de tomate y papa con síntomas de punta morada. Carrilles 1 - 4: Plantas de tomate colectadas en Antigua Guatemala (T9), Salamá (T21), San Jerónimo (T34) y Purulhá (T42). Carriles 5 - 10: Plantas de papa colectadas en Santa Cruz Balanyá (P48), Purulhá (P52), Zunil (P57) y Jalapa (P64, P67 y P68). CN: Control negativo (agua estéril). MP: Marcador de peso molecular DNA Ladder $3 \mathrm{~Kb}$ (SibEnzyme Ltd. $\left.{ }^{\circledR}\right)$. 
de incidencia de este patógeno en el total de muestras analizadas (Figura 3).

En papa, algunas muestras fueron positivas para fitoplasmas con los dos pares de cebadores universales y con el par de cebadores específicos en los municipios de Santa Cruz Balanyá, Purulhá, y Jalapa. Las muestras colectadas en los municipios de Zunil y San Juan Chamelco fueron negativas para fitoplasmas con los cebadores universales y con los específicos. En tomate, se identificaron muestras positivas para fitoplasmas con los dos pares de cebadores universales y/o con los específicos en los municipios de Antigua Guatemala, Salamá, San Jerónimo, Purulhá y Santa Cruz Balanyá (Tabla 1).

Con los cebadores específicos Cli.po.F/OI2c, seis muestras de papa fueron positivas para $C$. Liberibacter solanacerum, ya que amplificaron un fragmento esperado de aproximadamente $1,070 \mathrm{pb}$ (Figura 4), lo que representa un $26 \%$ de incidencia de este patógeno en las veintitrés muestras analizadas. En tomate, trece muestras fueron positivas para $C$. Liberibacter sola- nacerum, con los cebadores específicos (Figura 4), lo que representa un $27.6 \%$ de incidencia de este patógeno en las 47 muestras analizadas. La bacteria se detectó en tomate en los municipios de Antigua Guatemala, Villa Nueva, Amatitlán y San Jerónimo y Purulhá; en papa solamente se detectó en el municipio de Purulhá. La presencia mezclada del fitoplasma BLTVA y de la bacteria $C$. Liberibacter solanacearum, en una misma planta, se detectó en seis muestras de papa, que representan el 26\% de las muestras totales, y en tres muestras tomate, que representa el $6 \%$ de las muestras totales (Tabla 1).

\section{Discusión}

En virtud de que algunas muestras resultaron negativas a fitoplasmas en las PCR's directas con los pares de cebadores universales P1/P7 y P1/Tint, se decidió realizar la PCR anidada con la totalidad de las muestras colectadas. Los resultados positivos a fitoplasmas en

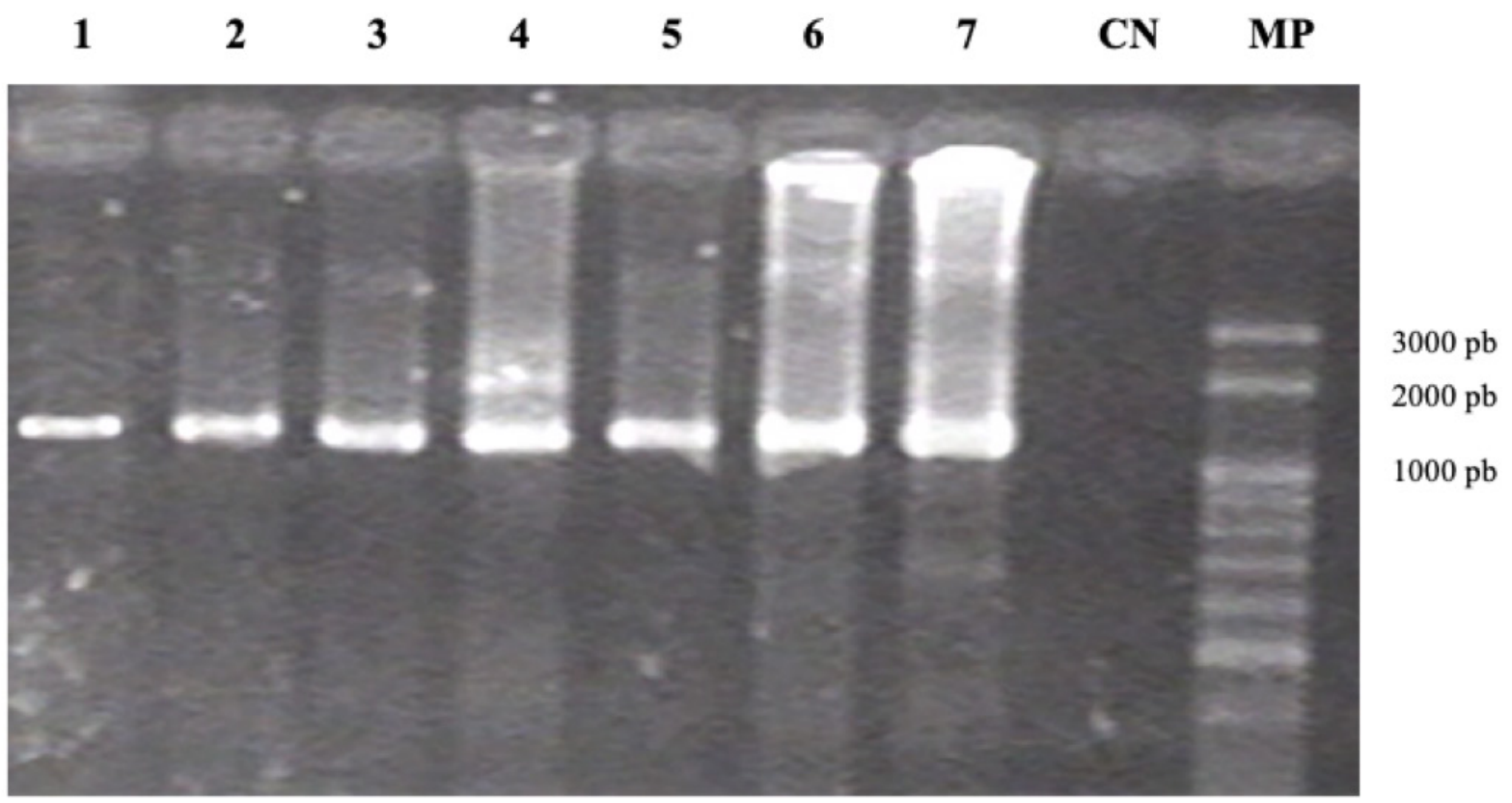

Figura 3. Productos amplificados por PCR con los cebadores fU5/BLTVAint a partir del ADN extraído de plantas de tomate y papa con síntomas de punta morada. Carrilles 1 - 3: Plantas de tomate colectadas en Antigua Guatemala (T9), Salamá (T22) y San Jerónimo (T38). Carriles 4 - 7: Plantas de papa colectadas en Santa Cruz Balanyá (P48), Purulhá (P52) y Jalapa (P64 y P67). CN: Control negativo (agua estéril). MP: Marcador de peso molecular DNA Ladder 3 Kb SibEnzyme Ltd.®) 
Tabla 1.

Detección de fitoplasmas asociados a la enfermedad de la punta morada, fitoplama BLTVA (16SrVI) y Candidatus Liberibacter solanaceraum en algunas de las principales zonas productoras de tomate y papa en Guatemala.

\begin{tabular}{|c|c|c|c|c|c|c|c|c|c|c|c|}
\hline No. & $\begin{array}{l}\text { Sitio de } \\
\text { colecta }\end{array}$ & $\begin{array}{l}\text { FTPMs } \\
\text { P1/P7 }\end{array}$ & $\begin{array}{l}\text { FTPMs } \\
\text { P1/Tint }\end{array}$ & BLVTA & CaLsol & No. & $\begin{array}{l}\text { Sitio de } \\
\text { colecta }\end{array}$ & $\begin{array}{l}\text { FTPMs } \\
\text { P1/P7 }\end{array}$ & $\begin{array}{l}\text { FTPMs } \\
\text { P1/Tint }\end{array}$ & $\begin{array}{c}\text { BLV- } \\
\text { TA }\end{array}$ & CaLsol \\
\hline $\mathrm{T} 1$ & \multirow{9}{*}{$\begin{array}{l}\text { Antigua } \\
\text { Guatemala }\end{array}$} & - & - & - & - & Т36 & \multirow{4}{*}{$\begin{array}{l}\text { San } \\
\text { Jerónimo }\end{array}$} & + & + & - & + \\
\hline $\mathrm{T} 2$ & & - & - & - & + & $\mathrm{T} 37$ & & + & + & - & - \\
\hline $\mathrm{T} 3$ & & - & - & - & - & $\mathrm{T} 38$ & & - & - & + & - \\
\hline $\mathrm{T} 4$ & & - & - & - & + & T39 & & - & - & + & + \\
\hline $\mathrm{T} 5$ & & - & - & - & - & T40 & \multirow{5}{*}{ Purulhá } & - & - & + & - \\
\hline T6 & & - & - & + & - & $\mathrm{T} 41$ & & - & - & + & - \\
\hline $\mathrm{T} 7$ & & - & - & + & - & $\mathrm{T} 42$ & & - & - & + & - \\
\hline T8 & & - & - & - & + & T43 & & - & - & + & + \\
\hline T9 & & + & + & + & - & $\mathrm{T} 44$ & & - & - & + & + \\
\hline $\mathrm{T} 10$ & \multirow{4}{*}{ Villa Nueva } & - & - & - & + & $\mathrm{T} 45$ & \multirow{6}{*}{$\begin{array}{l}\text { Santa } \\
\text { Cruz } \\
\text { Balanyá }\end{array}$} & - & - & + & - \\
\hline $\mathrm{T} 11$ & & - & - & - & - & $\mathrm{T} 46$ & & - & - & + & - \\
\hline $\mathrm{T} 12$ & & - & - & - & - & $\mathrm{T} 47$ & & - & - & + & - \\
\hline $\mathrm{T} 13$ & & - & - & - & - & $\mathrm{P} 48$ & & + & + & + & - \\
\hline T14 & \multirow{3}{*}{ Amatitlán } & - & - & - & + & P49 & & - & - & + & - \\
\hline T15 & & - & - & - & + & P50 & & - & - & + & - \\
\hline T16 & & - & - & - & + & P51 & \multirow{6}{*}{ Purulhá } & - & - & + & + \\
\hline T17 & \multirow{4}{*}{ Sanarate } & - & - & - & - & P52 & & + & + & + & + \\
\hline $\mathrm{T} 18$ & & - & - & - & - & P53 & & - & - & + & + \\
\hline T19 & & - & - & - & - & P54 & & - & - & + & + \\
\hline T20 & & - & - & - & - & P55 & & - & - & + & + \\
\hline $\mathrm{T} 21$ & \multirow{13}{*}{ Salamá } & + & + & - & - & P56 & & - & - & + & + \\
\hline $\mathrm{T} 22$ & & + & + & + & - & P57 & \multirow[t]{2}{*}{ Zunil } & - & - & - & - \\
\hline $\mathrm{T} 23$ & & + & + & - & - & P58 & & - & - & - & - \\
\hline $\mathrm{T} 24$ & & + & + & - & - & P59 & \multirow{5}{*}{ Patzicía } & - & - & - & - \\
\hline T25 & & + & + & - & - & P60 & & - & - & - & - \\
\hline $\mathrm{T} 26$ & & - & - & - & - & P61 & & - & - & - & - \\
\hline $\mathrm{T} 27$ & & - & - & - & - & P62 & & - & - & + & - \\
\hline $\mathrm{T} 28$ & & - & - & - & - & P63 & & - & - & + & - \\
\hline T29 & & + & + & - & - & P64 & \multirow{6}{*}{ Jalapa } & + & + & + & - \\
\hline $\mathrm{T} 30$ & & + & + & - & - & P65 & & + & + & + & - \\
\hline $\mathrm{T} 31$ & & + & + & - & - & P66 & & + & + & + & - \\
\hline T32 & & - & - & - & - & P67 & & + & + & + & - \\
\hline T33 & & - & - & - & - & P68 & & + & + & + & - \\
\hline T34 & \multirow{2}{*}{$\begin{array}{l}\text { San } \\
\text { Jerónimo }\end{array}$} & + & + & - & + & P69 & & + & + & + & - \\
\hline T35 & & - & - & - & + & P70 & $\begin{array}{l}\text { San Juan } \\
\text { Chamelco }\end{array}$ & - & - & - & - \\
\hline
\end{tabular}

Nota. Los números acompañados de la literal T representan muestras de tomate, los números acompañados de la literal P representan muestras de papa, FTPMs = Fitoplasmas asociados a la punta morada, BLTVA = Fitoplasma BLTVA $(16 \mathrm{SrVI}), \mathrm{CaLsol}=$ Candidatus Liberibacter solanacearum, $+=$ presencia,$-=$ ausencia 


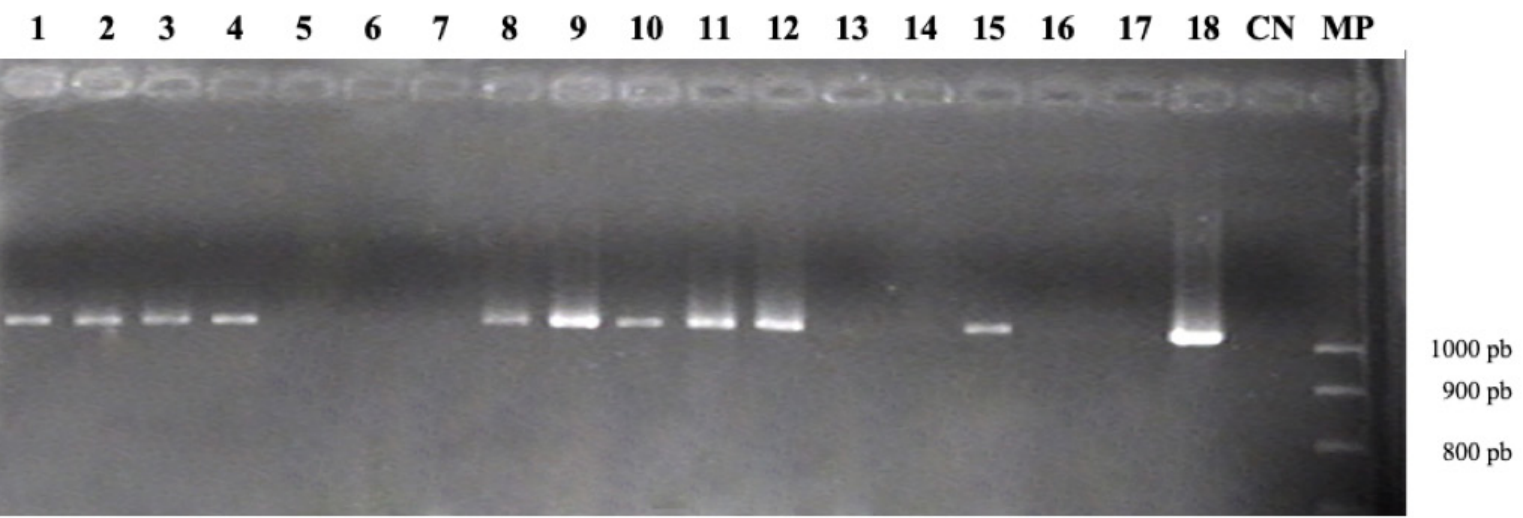

Figura 4. Productos amplificados por PCR con los cebadores Cli.po.F/OI2c a partir del ADN extraído de plantas de tomate y papa con síntomas de punta morada. Carriles 1 - 15 : Plantas de tomate colectadas en Antigua Guatemala (T2, T4 y T8), Villa Nueva (T10, T11, T12 y T13), Amatitlán (T15 y T16), San Jerónimo (T34, T36 y T39) y Purulhá (T41, T42 y T44). Carriles 16 - 18: Plantas de papa colectadas en Santa Cruz Balanyá (P49 y P50) y Purulhá (P56). $\mathrm{CN}$ : Control negativo (agua estéril). MP: Marcador de peso molecular DNA Ladder $1 \mathrm{~Kb}$ (invtrogen ${ }^{\circledR}$ ).

papa se incrementaron en más del $100 \%$ con esta metodología. De esta manera, de ocho muestras positivas obtenidas en las PCR directas, nueve muestras más fueron positivas con la PCR anidada, dando un total de 17 muestras positivas a fitoplasmas. Estos resultados ponen de manifiesto que la PCR anidada es más sensible que la PCR directa para la detección de fitoplasmas en papa, sobre todo cuando la concentración del patógeno es muy baja en el tejido utilizado para la extracción del ADN, resultados similares se han obtenido en otras investigaciones (Bertaccini et al., 2014; Nejat \& Vadamalai, 2010). Nejat y Vadamalai (2013), mencionan que existe una fluctuación estacional del fitoplasma en las plantas. En este trabajo, la colecta de tomate se hizo principalmente en época seca y la de papa se realizó en época lluviosa, lo cual, pudo afectar la concentración del fitoplasma en las muestras colectadas y por ende la diferencia registrada en el porcentaje de muestras que resultaron positivas en los dos cultivos. En cuanto a la distribución y concentración de los fitoplasmas, dentro de las plantas infectadas, se ha reportado que estos factores fluctúan entre las zonas foliares y radiculares debido al grado de infección de la enfermedad (Hogenhout et al., 2008; Christensen et al., 2004) lo que podría ser otro factor a considerar, ya que para esta evaluación se colectaron únicamente muestras foliares. Asimismo, ya que los fitoplasmas han sido descritos como habitantes del floema (Namba, 2019; Contaldo et al., 2016), es probable que la concentración de estos sea mayor en los tubérculos por ser depósitos de car- bohidratos provenientes del floema (Zúñiga-Sánchez et al., 2017), sin embargo, estos no fueron considerados en esta evaluación.

El incremento en el número de muestras positivas a fitoplasmas tras un segundo ciclo de amplificaciones mediante la PCR anidada, responde a que esta técnica tiene la ventaja de incrementar la concentración del amplicón de interés (Hong et al., 2019), siendo reportada en otros estudios para resolver la problemática de una baja concentración del fitoplasma en el tejido infectado (Bertaccini et al., 2014; Demeuse et al., 2016). Se ha demostrado que la PCR anidada es capaz de detectar concentraciones tan bajas de hasta cuatro células de fitoplasma, cuando están contenidas en la mezcla para la reacción de amplificación (Berges et al., 2000). Por tal razón, se detectó un incremento de resultados positivos después de registrarse resultados negativos en algunas muestras en las PCR's directas con los cebadores universales. Los resultados obtenidos en este estudio concuerdan con el primer reporte del fitoplasma BLVTA para Guatemala realizado por Munyaneza (2010), donde se asocia a la enfermedad de la punta morada con el cultivo de papa. Sin embargo, es de resaltar los resultados obtenidos en el presente estudio, ya que representan el primer reporte de la detección del fitoplasma BLTVA (16SrVI) en el cultivo de tomate para Guatemala.

La detección de muestras positivas para fitoplasmas con los cebadores universales, pero que resultaron negativas con los cebadores específicos fU5/BLTVAint, puede indicar la presencia de uno o varios fitoplasmas 
que pertenecen a otros grupos ya reportados y que están asociados a la misma enfermedad (Kumari et al., 2019; Santos-Cervantes et al., 2010), o al grupo recién descubierto (16SrII-X), el cual, también está asociado a la enfermedad de la punta morada (Omar et al., 2018). Para lograr la determinación correcta de las muestras que resultaron positivas para la presencia de fitoplasmas asociados a la enfermedad en este estudio, se recomienda realizar la secuenciación de los amplicones de las PCR's directas con los cebadores universales en trabajos futuros, como lo realizado por Caicedo y colaboradores (2015). De esta forma, podrían darse nuevos y certeros informes de otros fitoplasmas aún no reportados para Guatemala, los cuales estarían asociados a la enfermedad de la punta morada.

Los resultados negativos en las muestras sintomáticas pueden asociarse, en primer lugar, a una baja concentración de fitoplasmas, por lo que aún, la detección por PCR anidado con los cebadores específicos, no es suficientemente sensible, recomendándose el uso de PCR en tiempo real por su mayor sensibilidad de detección (Aliaga et al., 2018; Linck et al., 2017; Ustun et al., 2017). En segundo lugar, asumiendo que la primera ronda de amplificaciones por PCR con los cebadores universales fuera positiva, aunque no visualizable por la poca cantidad de amplicones generados; podría tratarse de otras especies de fitoplasmas asociados a la punta morada, por lo tanto, los cebadores específicos no generaron ningún amplicón a pesar de su mayor sensibilidad de detección.

Es importante mencionar que la alta incidencia (100\%) del fitoplasma BLTVA (Tabla 1), en los municipios de Jalapa y Santa Cruz Balanyá, concuerda con las observaciones de campo y las experiencias por parte de los agricultores locales. En ambos municipios, la alta incidencia y severidad de la enfermedad han obligado a un número significativo de agricultores, al abandono de la producción de papa, representando un serio problema económico y social para el área.

La detección de $C$. Liberibacter solanacearum, en muestras de papa, confirma la presencia de la bacteria en este cultivo en Guatemala (Palmieri et al., 2012; Secor et al., 2009), y su detección en muestras de tomate, determina la preferencia de especies de la familia Solanaceae como huéspedes de esta bacteria (Liefting et al., 2009; Melgoza-Villagómez et al., 2018). Al obtener resultados positivos únicamente para la bacteria en algunas muestras de papa y tomate, se confirma que, a nivel foliar, la presencia de $C$. Liberibacter solanacearum causa una sintomatología similar al fitoplasma BLTVA. Sin embargo, es importante resaltar que de acuerdo a Lin y colaboradores (2009), para el caso de papa, únicamente la bacteria está asociada a la enfermedad Zebra Chip, la cual, genera los síntomas típicos ya descritos en el tubérculo. Por otra parte, la alta incidencia de esta bacteria, en los campos de cultivo de papa en el municipio de Purulhá, ha generado graves pérdidas para los agricultores guatemaltecos del área. Esta situación también puede estar asociada a la presencia del fitoplasma BLTVA y $C$. Liberibacter solanacearum en una misma planta, ya que en dicho municipio se encontraron plantas de papa y tomate infectadas por ambos patógenos, lo cual incrementa la severidad de la enfermedad (Swisher et al., 2018; Gutiérrez-Ibáñez et al., 2013).

Debido a la similitud de síntomas foliares que generan los dos patógenos asociados a esta enfermedad, se hace indispensable el uso de técnicas moleculares para una detección efectiva $y$, a partir de esta, poder plantear las estrategias adecuadas para su manejo y control. Los resultados obtenidos en este estudio sugieren la presencia de otros fitoplasmas asociados a la enfermedad de la punta morada, diferentes al BLTVA. Ante esto, se sugiere realizar nuevos monitoreos, en campos de cultivo tanto de papa como de tomate, e incluir la secuenciación de los fragmentos amplificados en las PCR's directas para tener certeza, de que, efectivamente se detectan fitoplasmas y cuáles son los grupos de fitoplasmas presentes en el país. Además, debido al riesgo de transmisión a través tubérculos provenientes de plantas infectadas por fitoplasmas (Crosslin et al., 2011) y/o por $C$. Liberibacter solanacearum (Pitman et al., 2011), es necesario mantener un monitoreo constante en las zonas productoras de semilla de papa para confirmar que están libres de estos patógenos, así como evitar la diseminación de la enfermedad hacia áreas aún no afectadas.

Finalmente, queda confirmada la presencia del fitoplasma BLTVA y $C$. Liberibacter solanacearum, asociados a la enfermedad de la punta morada, en campos de cultivo de papa y tomate en Guatemala. Asimismo, la alta incidencia del fitoplasma BLTVA (73.9\%) en las muestras de papa, hacen que éste sea considerado como el agente asociado más importante en dicho cultivo, en comparación con la incidencia de la bacteria C. Liberibacter solanacearum $(27.6 \%)$. Por otra parte, en las muestras de tomate la incidencia del fitoplasma BLTVA (29.8\%) y C. Liberibacter solanacearum del $(27.6 \%)$ fue similar. No obstante, estos resultados destacan ampliamente ya que representan el primer reporte de la detección del fitoplasma BLTVA afectando el cultivo de tomate en Guatemala. Como una acción 
de control rápida, se recomienda no comprar semilla de papa sin brotes, ya que la sintomatología de punta morada puede observarse en los brotes, logrando así un reconocimiento temprano para evitar la diseminación de la enfermedad.

\section{Agradecimientos}

A la Dirección General de Investigación (Digi) por financiar la presente investigación a través de la partida presupuestaria 4.8.63.7.85.

\section{Referencias}

Abad, J. A., Bandla, M., French-Monar, R. D., Liefting, L. W., \& Clover, G. R. (2009). First report of the detection of 'Candidatus Liberibacter' species in zebra chip disease-infected potato plants in the United States. Plant Disease, 93(1), 108. https:// doi.org/10.1094/PDIS-93-1-0108C.

Alfaro-Fernández, A., Siverio, F., Cebrián, M. C., Villaescusa, F. J., \& Font, M. I. (2012). 'Candidatus Liberibacter solanacearum' associated with Bactericera trigonica-affected carrots in the Canary Islands. Plant Disease, 96(4), 581. https:// doi.org/10.1094/PDIS-10-11-0878-PDN

Aliaga, F., Hopp, E., Alvarez, E., \& Becerra, L. A. (2018). First report of a 'Candidatus Phytoplasma asteris' isolate associated with banana elephantiasis disease in Colombia. New Disease Reports, 37, 12. https://doi. org/10.5197/j.2044-0588.2018.037.012

Almeyda, L. I. H., Sánchez, S. J. A., Rubio, C. O., Ramos, V. O., \& Rocha, P. M. A. (2002). Detección molecular de fitoplasmas en insectos y maleza asociados al cultivo de la papa (Solanum tuberosum L.). En D. G. Fuentes (Ed.), Memorias del XXIX Congreso Internacional de la Sociedad Mexicana de Fitopatología, Monterrey, Nuevo León, México.

Almeyda, L. I. H., Sánchez, S. J. A, \& Garzón, T. J. A. (2004). Detección molecular de fitoplasmas en papa. En O. A. Flores, M. G. Gallegos \& M. O. García (Eds.), Memorias de Simposio Punta Morada (pp. 4-14). Coahuila, México.
Ben-Othmen, S., Morán, F. E., Navarro, I., Barbé, S., Martínez, C., Marco-Noales, E., ... López, M. (2018). 'Candidatus Liberibacter solanacearum' haplotypes D and E in carrot plants and seeds in Tunisia. Journal of Plant Pathology, 100, 197207. https://doi.org/10.1007/s42161-018-0045-7

Berges, R., Rott, M., \& Seemüller, E. (2000). Range of phytoplasma concentrations in various plant host as determined by competitive polymerase chain reaction. Bacteriology, 90(10), 1145-1152. https://doi.org/10.1094/PHYTO.2000.90.10.1145

Bertaccini, A., Duduk, B., Paltrinieri, S., \& Contaldo, N. (2014). Phytoplasmas and phytoplasma diseases: a severe threat to agriculture. American Journal of Plant Sciences, 5(12), 1763-1788. https://doi. org/10.4236/ajps.2014.512191

Bertolini, E., Teresani, G. R., Loiseau, M., Tanaka, F. A. O., Barb, S., Martínez, C., ... \& Cambra, M. (2015). Transmission of 'Candidatus Liberibacter solanacearum' in carrot seeds. Plant Pathology, 64, 276-285. https://doi.org/10.1111/ppa.12245

Caicedo, J., Crizón, M., Pozo, A., Cevallos, A., Simbaña, L., Rivera, L., \& Arahana, V. (2015). First report of 'Candidatus Phytoplasma aurantifolia' (16SrII) associated with potato purple top in San Gabriel-Carchi, Ecuador. New Disease Reports, 32, 20. https://doi. org/10.5197/j.2044-0588.2015.032.020

Christensen, N. M., Nicolaisen, M., Hansen, M., \& Schulz, A. (2004). Distribution of phytoplasmas in infected plants as revealed by real-time PCR and bioimaging. The American Phytopathological Society, 17(11), 1175-1184. https://doi. org/10.1094/MPMI.2004.17.11.1175

Contaldo, N., Satta, E., Zambon, Y., Paltrinieri, S., \& Bertaccini, A. (2016). Development and evaluation of different complex media for phytoplasma isolation and growth. Journal of Microbiological Methods, 127, 105-110. https:// doi.org/10.1016/j.mimet.2016.05.031

Crosslin, J. M., Hamlin, L. L., Buchman, J. L., \& Munyaneza, J. E. (2011). Transmission of potato purple top phytoplasma to potato tubers and daughter plants. American Journal of Potato Research, 88, 339-345. https://doi.org/10.1007/ s12230-011-9199-y 
Crosslin, J. M., \& Munyaneza, J. E. (2009). Evidence that the zebra chip disease and the putative causal agent can be maintained in potatoes by grafting and in vitro. Journal of Potato Research, 86, 183187. https://doi.org/10.1007/s12230-009-9070-6

Crosslin, J. M., Vandemark, G. J., \& Munyaneza, J. E. (2006). Development of a real-time, quantitative PCR for detection of the Columbia Basin potato purple top phytoplasma in plants and beet leafhoppers. Plant Disease, 90(5), 663-667. https://doi.org/10.1094/PD-90-0663

Delgado-Ortíz, J. C., Beltrán-Beache, M., CernaChávez, E., Aguirre-Uribe, L. A., Landero-Flores, J., Rodríguez-Pagaza, Y., \& Ochoa-Fuentes, Y. (2019). Candidatus Liberibacter solanacearum patógeno vascular de solanáceas: Diagnóstico y control. Revista Especializada en Ciencias Químico-Biológicas, 22, 1-12. https://doi. org/10.22201/fesz.23958723e.2019.0.177

Demeuse, K. L., Grode, A. S., \& Szendrei, Z. (2016). Comparing qPCR and nested PCR diagnostic methods for aster yellows phytoplasma in aster leafhoppers. Plant Disease, 100(2), 2513-2519. https://doi.org/10.1094/PDIS-12-15-1444-RE

El-banna, M., Mikhail, M. S., Farag, A. G., \& Mohammed, A. M. (2007). Detection of phytoplasma in tomato and pepper plants by electron microscopy and molecular biology based methods. Egyptian Journal of Virology, 4, 93-111.

Garzón, T. J. A., Bujanos, M. R., Velarde, F. S., Marín, J. A., Parga, T. V. M., Aviles, G. M. C... Garzón C. J. A. (2004). Bactericera (Paratrioza) cockerelli Sulc., vector de fitoplasmas en México. En O. A., Flores, M. G. Gallegos \& M. O. García (Eds.), Memorias del Simposio Punta Morada de la Papa (64-83). Coahuila, México.

Goolsby, J. A., Bextine, B., Munyaneza, J. E., \& Setamou, M. (2007). Seasonal abundance of sharpshooters, leafhoppers, and psyllids associated with potatoes affected by zebra chip disorder. Subtropical Plant Science, 59, 15-23.

Greenway, G.A. \& Rondon, S. (2018). Economic impacts of Zebra Chip in Idaho, Oregon, and Washington. American Journal of Potato Research, 95, 362-367. https://doi.org/10.1007/ s12230-018-9636-2
Gutiérrez-Ibáñez, A. T., Laguna-Cerda, A., RojasMartínez, R., González-Garza, R., \& SalgadoSiclán, M. L. (2012). Molecular detection and classification of the phytoplasma that causes purple top in potatoes (Solanum tuberosum) in the State of Mexico. Ciencia e Investigación Agraria, 39(2), 339-346. http://dx.doi.org/10.4067/S071816202012000200010.

Gutiérrez-Ibáñez, A. T., Ricardo, J., Pale, S., Cerda, A. L., Ramírez, J. F., Balbuena, A., \& Alvarado, O. (2013). Detección de Ca Liberibacter solanacearum y fitoplasmas en cultivo de papa (Solanum tuberosum L.) en el Valle de Toluca. Revista Colombiana de Biotecnología, 15(1), 145-149.

Hansen, A. K., Trumble, J. T., Stouthamer, R., \& Paine, T. D. (2008). A new huanglongbing species, 'Candidatus Liberibacter psyllaurous', found to infect tomato and potato, is vectored by the psyllid Bactericera cockerelli (Sulc). Applied and Environmental Microbiology, 74(18), 5862-5865. https://doi.org/10.1128/AEM.01268-08

Hogenhout, S. A., Oshima, K., Ammar, E., Kakizawa, S., Kingdom, H. N., \& Namba, S. (2008). Phytoplasmas: bacteria that manipulate plants and insects. Molecular Plant Pathology, 9(4), 403-423. https://doi.org/10.1111/j.13643703.2008.00472.x

Hong, Y., Luo, Y., Yi, J., He, L., Dai, L., \& Yi, T. (2019). Screening nested-PCR primer for 'Candidatus Liberibacter asiaticus' associated with citrus Huanglongbing and application in Hunan, China. PLOS ONE, 14(2), e0212020. https://doi. org/10.1371/journal.pone.0212020

Kumari, S., Nagendran, K., Bahadur-Rai, A., Singh, B., Pratap-Rao, G., \& Bertaccini, A. (2019). Global status of phytoplasma diseases in vegetable crops. Frontiers in Microbiology, 10, 1349. https://doi. org/10.3389/fmicb.2019.01349

Lee, I. M., Bottner, K. D., Munyaneza, J. E., Secor, G. A., \& Gudmestad, N. C. (2004). Clover proliferation group (16SrVI) subgroup A (16SRVI-A) phytoplasma is a probable causal agent of potato purple top disease in Washington and Oregon. Plant Disease, 88(4), 429. https:// doi.org/10.1094/PDIS.2004.88.4.429B. 
Liefting, L. W., Pérez-Egusquiza, Z. C., Clover, G. R. G., \& Anderson, A. D. (2008). A new 'Candidatus liberibacter' species in solanum tuberosum in New Zealand. Plant Disease, 92(10), 1474-1474. https://doi.org/10.1094/PDIS-92-10-1474A.

Liefting, L. W., Weir, B. S., Pennycook, S. R., \& Clover, G. R. G. (2009). 'Candidatus Liberibacter solanacearum', associated with plants in the family Solanaceae. International Journal of Systematic and Evolutionary Microbiology, 59, 2274-2276. https://doi.org/10.1099/ijs.0.007377-0

Lin, H., Doddapaneni, H., Munyaneza, J. E., Civerolo, E. L., Sengoda, V. G., Buchman, J. L., \& Stenger, D. C. (2009). Molecular characterization and phylogenetic analysis of 16S rRNA from a new 'Candidatus Liberibacter' strain associated with zebra chip disease of potato (Solanum tuberosum L.) and the potato psyllid (Bactericera cockerelli). Journal of Plant Pathology, 91(1), 215-219.

Linck, H., Krüger, E., \& Reineke, A. (2017). A multiplex TaqMan qPCR assay for sensitive and rapid detection of phytoplasmas infecting Rubus species. PLoS ONE, 12(5), e0177808. https://doi. org/10.1371/journal.pone. 0177808

Longoria-Espinoza, R. M., Douriet-Gámez, N. R., Lopez-Meyer, M., Quiroz- Figueroa, F., BuenoIbarra, M., Méndez-Lozano, J., ... Leyva-López, N. E. (2013). Differentially regulated genes in Solanum tuberosum in response to Mexican potato purple top phytoplasma infection. Physiologicla and Molecular Plant Pathology, 81, 33-44. https://doi.org/10.1016/j.pmpp.2012.10.001

Lorenz, K. H., Schneider, B., Ahrens, U., \& Seemüller, E. (1995). Detection of the apple proliferation and pear decline phytoplasmas by PCR amplification of ribosomal and nonribosomal DNA. Phytopathology, 85(7), 771-776.

Maramorosch, K. (1998). Potato purple top wilt. Segundo Simposium Internacional de Papa (pp. 13-15). Toluca, Estado de México.

Mejía, L., Sánchez-Pérez, A., Méndez, L., Maxwell, D. P., Gilberson, R. L., Rivera, G. A., \& Secor, G. A. (2010). Preliminary report on association of "Candidatus Liberibacter solanacearum" with field grown tomatoes in Guatemala. Tomato Genetics Cooperative, 60, 54-57.
Melgoza-Villagómez, C. M., León-Sicarios, C., López-Valenzuela, J. A., Hernández-Espinal, L. A., Velarde-Félix, S., \& Garzón-Tiznado, J. A. (2018). Presencia de Candidatus Liberibacter solanacearum en Bactericera cockerelli Sulc asociada con enfermedades en tomate, chile y papa. Revista Mexicana de Ciencias Agrícolas, 9(3), 499-509.

Ministerio de Agricultura, Ganadería y Alimentación. (2016). El Agro en cifras, 2016. Guatemala: Autor.

Munyaneza, J. E. (2005). Purple top disease and beet leafhopper transmitted virescence agent (BLTVA) phytoplasma in potatoes of the Pacific Nothwest of the United States. En A. J. Haverkort \& P. C. Struik (Eds.), Potato in progress, science meets practice (pp. 211-220). Proceedings of the Potato Congress. Emmeloord, The Netherlands.

Munyaneza, J. E. (2010). Emerging leafhoppertransmitted phytoplasma diseases of potato. Southwestern Entomologist, 35(3), 451-456. https://doi.org/10.3958/059.035.0331

Munyaneza, J. E., Crosslin, J. M., \& Ing-Ming, L. (2007). Phytoplasma diseases and insect vectors in potatoes of the Pacific northwest of the United States. Bulletin of Insectology, 60(2), 181-182.

Munyaneza, J. E., Crosslin, J. M., \& Upton, J. E. (2007). Association of Bactericera cockerelli (Homoptera: Psyllidae) with "Zebra Chip," a new potato disease in Southwestern United States and Mexico. Journal of Economic Entomology, 100(3), 656-663. https://doi.org/10.1603/00220493(2007)100[656:AOBCHP]2.0.CO;2

Munyaneza, J. E., Crosslin, J. M., \& Upton, J. E. (2006). Beet leafhopper (Hemiptera: Cicadellidae) transmits the Columbia Basin potato purple top phytoplasma to potatoes, beets, and weeds. Journal of Economic Entomology, 99(2), 268272. https://doi.org/10.1603/0022-0493-99.2.268

Munyaneza, J. E., Fisher, T. W., Sengoda, V. G., Garczynski, S. F., Nissinen, A., \& Lemmetty, A. (2010). First report of "Candidatus Liberibacter solanacearum" associated with psyllid-affected carrots in Europe. Plant Disease, 94(5), 639. https://doi.org/10.1094/PDIS-94-5-0639A

Munyaneza, J. E., Goolsby, J. A., Crosslin, J. M., \& Upton, J. E. (2007). Further evidence the zebra 
chip potato disease in the Lower Rio Grande Valley of Texas is associated with Bactericera cockerelli. Subtropical Plant Science, 59, 30-37.

Namba, S. (2019). Molecular and biological properties of phytoplasmas. Proceedings of the Japan Academy Series B, 95(7), 401-418. https://doi. org/10.2183/pjab.95.028.

Nejat, N., \& Vadamalai, G. (2010). Phytoplasma detection in coconut palm and other tropical crops. Plant Pathology Journal, 9(3), 112-121. https://doi.org/10.3923/ppj.2010.112.121

Nejat, N., \& Vadamalai, G. (2013). Diagnostic techniques for detection of phytoplasma diseases: past and present. Journal of Plant Diseases and Protection -New Series-, 120(1), 16-25. https:// doi.org/10.1007/BF03356449

Omar, A., Aljmhan, K., Abdullah, S., \& Pérez-López, E. (2018). Potato purple top disease associated with the novel subgroup 16SrII-X phytoplasma. International Journal of Systematic and Evolutionary Microbiology, 68, 3678-3682. https://doi.org/10.1099/ijsem.0.003033

Palmieri, M., Mejía, F., Polanco, M., Mansilla, F., Donis, I., Catalán, A., ... López, A. (2012). Caracterización de patógenos, vectores $y$ hospederos de la papa rayada en Guatemala (Proyecto FODECYT No. 077-2006). Guatemala: Consejo Nacional de Ciencia y Tecnología, Universidad del Valle de Guatemala.

Pitman, A. R., Drayton, G. M., Kraberger, S. J., Genet, R. A., \& Scott, I. A. W. (2011). Tuber transmission of 'Candidatus Liberibacter solanacearum' and its association with zebra chip on potato in New Zealand. European, 129, 389-398. https://doi. org/10.1007/s10658-010-9702-1

Santos-Cervantes, M. E., Chávez-Medina, J. A., AcostaPardini, J., Flores-Zamora, G. L., MéndezLozano, J., \& Leyva-López, N. E. (2010). Genetic diversity and geographical distribution of phytoplasmas associated with potato purple top disease in Mexico. Plant Disease, 94(250), 22-25. https://doi.org/10.1094/PDIS-94-4-0388
Secor, G. A., \& Rivera-Varas, V. V. (2004). Emerging diseases of cultivated potato and their impact on Latin America. Revista Latinoamericana de La Papa, 1, 1-8.

Secor, G. A., Rivera, V. V, Pathology, P., Dakota, N., Abad, J. A., Lee, I., ... De Boer, S. H. (2009). Association of 'Candidatus Liberibacter solanacearum' with zebra chip disease of potato established by graft and psyllid transmission, electron microscopy, and PCR. Plant Disease, 93(6), 574-583. https://doi.org/10.1094/pdis-936-0574

Smart, C. D., Schneider, B., Blomquist, C. L., Guerra, L. J., Harrison, N. A., Ahrens, U., ... Kirkpatrick, B. C. (1996). Phytoplasma-specific PCR primers base on sequences of the 16S-23S rRNA spacer region. Applied and Environmental Microbiology, 62(8), 2988-2993.

Swisher, K. D., Munyaneza, J. E., Velásquez-Valle, R., \& Mena-Covarrubias, J. (2018). Detection of pathogens associated with psyllids and leafhoppers in Capsicum annuum L. in the Mexican stages of Durango, Zacatecas and Michoacán. Plant Disease, 102, 146-153. https:// doi.org/10.1094/PDIS-05-17-0758-RE

Teresani, G. R., Bertolini, E., Alfaro-Fernandez, A., Martinez, C., Tanaka, F. A. O., Kitajima, E. W., ... Lopez, M. M. (2014). Association of 'Candidatus Liberibacter solanacearum' with a vegetative disorder of celery in Spain and development of real-time PCR method for its detection. Phytopathology,104, 80-811. https:// doi.org/10.1094/PHYTO-07-13-0182-R

Ustun, R., Yol, E., Ikten, C., Catal, M., \& Uzun, B. (2017). Screening, selection and real-time qPCR validation for phytoplasma resistance in sesame (Sesamum indicum L.). Euphytica, 213, 159. https://doi.org/10.1007/s10681-017-1936-y

Zuñiga-Sánchez, E., Martínez-Barajas, E., ZavaletaMejía, E., \& Gamboa, A. (2017). El floema y la ruta simplástica durante la formación de órganos de demanda. Revista Fitotecnia Mexicana, 40(3), 249-259. 